\title{
Study on the influence of composite soil on the slope stability of farmland during in land consolidation
}

\section{Chuan Zhang ( $\sim 276764242 @ q q . c o m$ )}

China University of Mining Technology;Yunnan Agricultural University https://orcid.org/0000-0001-

8725-3606

\section{Wujiang Liu}

Yunnan Agricultural University

\section{Xiaoshun Li}

China University of Mining Technology: China University of Mining and Technology

\section{Song Yang}

Yunnan Agricultural University

Chao Xu

Yunnan Agricultural University

\section{Yuexiang Wang}

China University of Mining and Technology

\section{Qingsong Duan}

Yunnan Agricultural University

Honggang Zheng

Yunnan Agricultural University

\section{Research Article}

Keywords: Slope farmland, Land consolidation, Composite soil, Soil shear strength, Slope safety factor

Posted Date: June 21st, 2021

DOl: https://doi.org/10.21203/rs.3.rs-216321/v1

License: (c) (i) This work is licensed under a Creative Commons Attribution 4.0 International License. Read Full License

Version of Record: A version of this preprint was published at Environmental Earth Sciences on March 1st, 2022. See the published version at https://doi.org/10.1007/s12665-022-10266-3. 


\title{
Study on the influence of composite soil on the slope stability of farmland during in land consolidation
}

\author{
Chuan Zhang ${ }^{1,2} \cdot$ Wujiang Liu ${ }^{2} \cdot$ Xiaoshun $\mathrm{Li}^{1 凶}$. Song Yang ${ }^{2 \bowtie} \cdot$ Chao $\mathrm{Xu}^{2}$. \\ Yuexiang Wang ${ }^{1} \cdot$ Qingsong Duan ${ }^{2} \cdot$ Honggang Zheng ${ }^{2}$
}

Received: 20 Dec 2020 / Accepted: *** 2021

\begin{abstract}
To improve the stability of sloping farmland, the optimal ratio parameter of composite soil was determined. Single and mixed composite soils were prepared with three improved materials of glutinous rice glue, wood fibres and coarse sand for indoor direct shear tests and pot experiments. Based on the different moisture and soil contents, the shear strength, cohesion, and internal friction angle of the composite soil were analyzed, and the proportioning parameters were adjusted according to the suitability of plant growth. Slope stability analysis was performed in combination with the actual case of slope farmland improvement. The research results show that (1) different soil improvement materials are affected by moisture in different sections. The maximum shear strengths of composite soil with glutinous rice glue, wood fibre, and coarse sand correspond to $11 \%, 14 \%$ and $32 \%$ of the optimal moisture content respectively. The change in the content of the modified material will affect the soil structure, and the shear strengths of the single composite soils are the highest when the content of the modified material are $1.5 \%, 5 \%$ and $15 \%$. (2) According to the shear strength and the suitability of plant growth, the contents of the glutinous rice glue, wood fibre, and coarse sand of the mixed composite soil were determined by the optimal ratio parameters of $1.5 \%: 2.5 \%: 15 \%$. (3)In this application, the minimum safety factor of mixed (1.5\% glutinous rice glue, $2.5 \%$ wood fibre, and $15 \%$ coarse sand) composite soil is higher than that of single composite soil at slopes of $10^{\circ}, 15^{\circ}$, and $20^{\circ}$. Under different water contents, the overall stability of the mixed composite soil slope improves.
\end{abstract}

Keywords Slope farmland · Land consolidation · Composite soil · Soil shear strength $\cdot$ Slope safety factor

\section{Introduction}

Soil loss on sloping farmland is a common problem related to land use in hilly areas. Sloping farmland has large slopes, loose soil, and high erodibility. During the rainy season, the soil has high water content and heavy viscosity, which is not conducive to water infiltration; When the water content of the soil is high, the soil will crack and break, and fine grains will gradually be lost, thereby causing the degradation of the slope of the farmland and its ecological function.

$\triangle$ Xiaoshun Li（zhangchuan0569@sina.com） $\quad \square$ Yang Song（417642930@qq.com）

1 Research Center for Transition Development and Rural Revitalization of Resource-based Cities in China,

China University of Mining and Technology, Xuzhou, 221116, China

2 Engineering Research Center of Science and Technology of Land and Resources, Yunnan Agricultural University, Kunming, 650201, China 
Relevant studies have shown that improvement of soil due to the addition of a certain amount of material has the effects of increasing the shear strength of soil, increasing the moisture content, improving the soil structure, and reducing soil erosion(Xiao et al. 2017; Le et al. 2020; Liu et al. 2012;Pan et al. 2003;Sun et al. 2020; Xi et al. 2018). Therefore, in the improvement of sloping farmland, improving the soil structure and stability of sloping farmland is particularly important for plant growth.

At present, research on the soil properties of soil conditioner has attracted widespread attention from scholars at home and abroad, especially research on the effects of different materials on the soil stability, in the fields of agricultural engineering and geotechnical engineering. In the field of agricultural engineering, some scholars have used a biochar(Peng et al. 2019), carbon-based(Chai et al. 2017), application of soil amendments (ferrous sulfate FES, aluminium sulfate ALS, polyacrylamide PAM) and soil disinfectants (pentachloronitro benzene PCNB) (Ji et al. 2011), combined application of soil amendments(Pan et al. 2008), earthworm manure(Shao et al. 2020), organic materials (straw mulch, biomass charcoal and pig manure) (Zhang et al. 2017) and other soil amendments to study the effect of soil agglomeration on slope farms. Body stability, soil agglomeration, organic carbon (OC) content, soil water holding capacity and effective soil reservoir capacity, soil infiltration rate and water holding capacity, water retention, sand control, and fertilizer control have good control effects, but there are few studies on the effect of soil amendment application on the soil mechanical properties of sloping farmland. Research on the mechanical properties of the soil of sloping farmland mainly focuses on different land use types( $\mathrm{Li}$ 2017), farming methods (Du et al. 2018), rainfall intensities and slopes (Yuan et al. 2015), soil particles (Fan 2019), soil bulk densities and moisture contents (Zhang et al. 2020), plants (Ding et al. 2017; Pu et al. 2014; Shi et al. 2016) and other influencing factors on the response the of soil shear strength, without considering the effect of soil amendments on the mechanical properties of soil. In the field of geotechnical engineering, some scholars have found that the influence of the ratio of rock blocks on the shear strength of cemented soil-rock mixtures depends on the combination of the skeletal effect of rock blocks and the cementation effect of the mixture (Jin et al. 2017; Tang et al. 2018); for the resistance of soil-rock mixtures, the shear strength largely depends on the characteristics of its internal stone content. With increasing the stone content, the internal friction angle increases obviously, while the cohesive force shows a decreasing trend. The cohesive force mainly depends on the internal fine particles of the components (Xu et al. 2011; Xu et al. 2013; Yang et al. 2016); When using curing agent PX to study the strength of sand solidification, it is observed that curing agent PX will form a gel, which changes the adhesion strength between the soil particles, thereby resulting in an increase in the overall strength, and there is an optimal addition amount (Liu et al. 2017; Guo et al. 2017). When using the SH curing agent to strengthen the loess, it is observed that the curing agent effectively improves the shear strength of the loess. The internal friction angle and cohesive force of the solidified loess increase with the increase in the content, dry density and the age The elongation shows an increasing trend, and it decreases significantly with the increase in the moisture content (Cheng 2014); the addition of coconut shell fibres to clay indicates that the increase in fibre content demonstrates that the principal stress gradually increases when the reinforced soil is damaged (Maliakal et al. 2013); when discrete palm fibres are used, it is observed that the incorporation of fibres reduces the pre-consolidation pressure of the soil, and increases the shear strength and friction angle (Estabragh et al. 2013). The incorporation of fibres makes the soil have a stronger toughness, and 
the shear strength does not immediately reach the peak decrease, but maintains a certain strength for a period of time and then decreases. Due to the connection of the fibres, the residual strength of the damaged soil is still larger than that of plain soil(He 2018).

In summary, on the one hand, scholars have performed much research on the improvement in soil properties on slopes with a single material, while there are few studies on the improvement in soil properties on slopes with multiple materials. On the other hand, the field of agricultural engineering mainly focuses on the improvement in the performance related to soil water and fertilizer retention, but the improvement in the soil stability is ignored, while the relative lack of research on the slope stability of soil and the benefits for plant growth are considered. In addition, the field of geotechnical engineering mainly focuses on the enhanced mechanical properties of soil, and the greater the shear strength, the better mechanical performance, but this is not conducive to plant growth. Therefore, in this paper, three materials, glutinous rice glue, wood fibre, and coarse sand, were separately prepared and combined with different moisture contents and content differences, while direct shear tests on unsaturated composite soil were carried out to study the characteristics of soil shear strength and its changing laws. The optimal proportion parameters of the composite soil were determined, and the improvement of sloping farmland was taken as an example to analyse the stability of the composite soil layer of the farmland. The research results can provide a theoretical basis and application foundation for land improvement projects.

\section{Materials and methods}

\section{Test materials}

The soil used for this study is red loam, which is derived from the soil of farmland slopes in the valley area of Binchuan County. Its parent material is slope deposits and alluvial deposits. Due to the short time of soil formation, the degree of maturation is not high, the soil profile experiences substantial leaching. In the mineral layer, the soil fertility is relatively low, and the texture is light (Table 1). Glutinous rice glue (Fig.1-a) is an environmentally friendly adhesive made from glutinous rice starch. It has a wide range of applications and long viscosity. It is produced by Tianyi Wallpaper Co., Ltd. Wood fibre (Fig.1-b) is a natural plant cellulose fibre with an irregular fan-shaped structure, super hydrophilic properties, fast moisture absorption, large moisture absorption, 99\% organic content, and $8 \%$ ash content. The fibre length is in the range of $3 \sim 10 \mathrm{~mm}$, the PH is 6, and the fibre is produced by Southeast Wood Fibre Technology Co., Ltd. The test sand (Fig.1-c) is machine-made sand, which has rock particles with a particle size of less than $4.75 \mathrm{~mm}$ that are processed by soil removal, broken by machinery, and sieved. The shape of the particles is generally triangular, rectangular, and square. The surface is rough and angular.

Table 1 Basic physical properties of soil samples

\begin{tabular}{ccccc}
\hline Air-dry moisture & Maximum dry density & Optimum moisture & Liquid limit & Plastic limit \\
content $/ \%$ & $/ \mathrm{g} \cdot \mathrm{cm}^{-3}$ & content $/ \%$ & $1 \%$ & $1 \%$ \\
6.00 & 1.43 & 32.00 & 53.28 & 24.63 \\
\hline
\end{tabular}




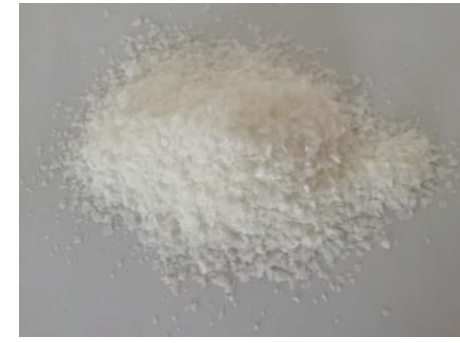

(a)Glutinous rice glue

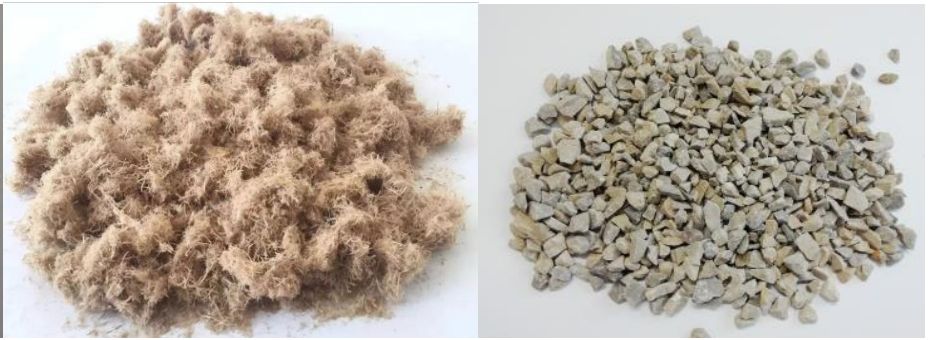

(b) Wood fibre

(c)Coarse sand

Fig. 1 Three red soil improved materials

\section{Sample preparation}

There were three content gradients of $0.5 \%, 1.5 \%$, and $2.5 \%$ for glutinous rice glue; three content gradients of $1 \%, 2.5 \%$, and $5 \%$ for wood fibre; and four content gradients of $5 \%, 10 \%$, $15 \%$, and $20 \%$ for coarse sand. The gradients were mixed with red soil, and plain soil was used as the control group. All samples were designed to make 4 composite soil samples with different moisture contents of $30 \%, 32 \%, 34 \%$, and $36 \%$. However, the experiment showed that glutinous rice glue and wood fibre have high water absorption. Too low of a mixing water content is not conducive to the full mixing of soil particles. Therefore, more water is used for mixing, but the composite soil formed by mixing is due to moisture. If the direct shear test is performed directly, the data are inconsistent, the law is not obvious, and the test results are inaccurate. Therefore, the air-drying method is used to control the moisture content of the composite soil and make multiple samples with different moisture contents. The moisture content of the glutinous rice glue composite soil was controlled to 7 , which was $3 \%, 5 \%, 7 \%, 9 \%, 11 \%, 13 \%$, and $15 \%$, and that of the wood fibre composite soil was 5 , which was $7 \%, 14 \%, 21 \%, 28 \%$, and $35 \%$. Glutinous rice glue, wood fibre, coarse sand, and plain soil were made into 21, 15, 16, and 4 different treatments, for a total of 56 treatments, and each treatment was repeated 4 times.

\section{Test method}

Studies have shown that if the vertical pressure is more than $400 \mathrm{kPa}$, the vertical pressure and the shear strength of the soil exhibit a linear relationship. If the vertical pressure is below $100 \mathrm{kPa}$, the friction between the shear boxes will increase, which will affect the accuracy of the test. Therefore, this article uses the ZJ strain control direct shear instrument produced by Nanjing soil instrument factory Co., Ltd, to perform the shear tests, and the shear rate was $4 \mathrm{r} / \mathrm{min}$. To obtain a complete shear strength curve, the 4 levels of vertical pressure for each processed sample were $100 \mathrm{kPa}, 200 \mathrm{kPa}, 300 \mathrm{kPa}$, and $400 \mathrm{kPa}$. In strict accordance with the norms "Geotechnical Test Method Standards", for the provisions of the fast shear test(Nanjing hydraulic research institute 1999), the Coulomb formula is used to obtain the cohesion and internal friction angle of the composite soil under different conditions:

$$
\tau=\sigma \cdot \tan \varphi+c
$$

In the formula, $\tau$ is The shear strength of the soil $(\mathrm{kPa}) ; \sigma$ is the vertical pressure $(\mathrm{kPa})$; $\varphi$ is the angle of internal friction $\left(^{\circ}\right)$; and $c$ is the cohesion $(\mathrm{kPa})$.

\section{Data analysis and processing}


Origin2017 is used to process and analyse the measurement data and draw charts. Geostudio software is a specialized software for slope stability analysis. The simulation in this paper adopts the Morgenstern-rice method to calculate and analyse the slope stability(He et al. 2019). In the model simulation of this article, the slope is set in combination with the actual case. During the simulation, only the internal friction angle and cohesion of each test group under different water content conditions are changed, and the most dangerous slip surface of the same slope under different conditions is calculated for the corresponding minimum safety factor.

\section{Results and analysis}

\section{Analysis of shear strength of single composite soil with different water contents}

When the moisture content of composite soil changes, its shear strength also changes, and composite soils of different materials exhibit different performances(Table 2 and Fig.2). With increasing water content, the shear strength of plain soil is relatively stable when the water content is in the range of 30 32\% and then slowly decreases. The internal friction angle fluctuates slightly, the floating range is between $22.06 \sim 22.4^{\circ}$, the change rule is not obvious, and the cohesive force continues to decrease. The shear strength and internal friction angle of glutinous rice glue composite soil shows a trend of first decreasing, then increasing and then decreasing. The cohesion increases slowly at water contents of 3\% 7\%, and at the 7\% 15\% stage, it increases rapidly and then decreases rapidly. When the moisture content is $3 \%$, the glutinous rice glue is dehydrated and solidified and mostly exists in the form of solid particles in the composite soil. When the moisture increases, the glutinous rice glue gradually absorbs water and softens becoming "gelatinous", the cementing effect is enhanced, and the cohesive force increases. The internal friction angle is reduced. When the moisture content is $11 \%$, the shear strength, internal friction angle and cohesive force all reach maximum values. The shear strength and cohesive force of wood fibre composite soil showed a significant decline after the moisture content increased to $14 \%$. When the water content is $21 \%$, the internal friction angle reaches a maximum value; when the water content increases to $28 \%$, it shows a rapid decreasing trend. The hysteresis phenomenon of the internal friction angle may be due to the increase in soil moisture, and the structure between the wood fibre and the soil particles and the structure between the soil particles and the soil particles are changed by water, and re-occluding occurs; therefore, the contact area changes, thereby resulting in a certain internal friction angle. The water cut interval increases slightly first, which occurs in the water interval of $14-21 \%$ in this study. The shear strength, internal friction angle and cohesive force of coarse sand composite soil first increase and then decrease. When the water content is $32 \%$, the three values are the largest; The internal friction angle and cohesive force are affected by the changes in the influence of moisture are basically the same, and there is no hysteresis(Fig.2). Because the soil amendment and soil particles combine to form a certain strength, the effect of moisture content on the soil will be reduced.

Table 2 Changes in shear strength of single composite soil under different water content conditions

(kpa)

\begin{tabular}{cccccc}
\hline \multirow{2}{*}{ category } & Moisture content $/ \%$ & \multicolumn{3}{c}{ Vertical pressure /kpa } \\
& & $100 \mathrm{kpa}$ & $200 \mathrm{kpa}$ & $300 \mathrm{kpa}$ & $400 \mathrm{kpa}$ \\
\hline Plain soil & $30 \%$ & 76.81 & 117.66 & 158.50 & 199.34 \\
\hline
\end{tabular}




\begin{tabular}{cccccc}
\hline & $32 \%$ & 75.98 & 117.22 & 158.46 & 199.71 \\
& $34 \%$ & 68.69 & 109.21 & 149.73 & 190.25 \\
& $36 \%$ & 67.16 & 107.93 & 148.70 & 189.48 \\
Glutinous rice glue & $3 \%$ & 136.44 & 213.44 & 315.56 & 401.84 \\
composite soil & $5 \%$ & 99.43 & 147.46 & 185.03 & 234.2 \\
& $7 \%$ & 89.71 & 119.99 & 142.04 & 178.3 \\
& $11 \%$ & 213.49 & 295.73 & 377.56 & 471.64 \\
& $13 \%$ & 268.8 & 362.34 & 480.07 & 593.11 \\
Wood fibre & $15 \%$ & 97.33 & 124.41 & 179.9 & 213.2 \\
composite soil & $7 \%$ & 439.64 & 479.2 & 534.9 & 617.24 \\
& $14 \%$ & 372.87 & 549.89 & 587.93 & 601.71 \\
& $21 \%$ & 261.04 & 242 & 464.39 & 508.18 \\
Coarse sand & $28 \%$ & 131.38 & 200.87 & 266.56 & 361.76 \\
composite soil & $35 \%$ & 34.11 & 99.19 & 109.09 & 128.35 \\
& $30 \%$ & 60.56 & 106.28 & 152.00 & 197.72 \\
& $32 \%$ & 71.96 & 119.23 & 166.50 & 213.77 \\
& $34 \%$ & 66.19 & 111.85 & 157.51 & 203.16 \\
\hline
\end{tabular}

1 Note: In the three single composite soils, the mixing amounts of glutinous rice glue, wood fibre, and coarse sand 2 are $1.5 \%, 5 \%$, and $5 \%$, respectively.

3

4

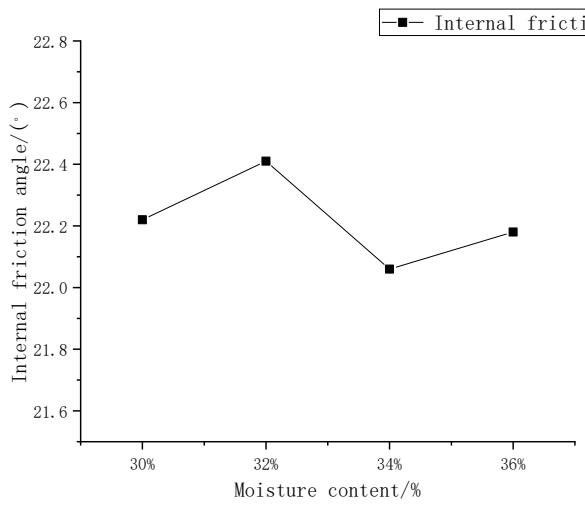

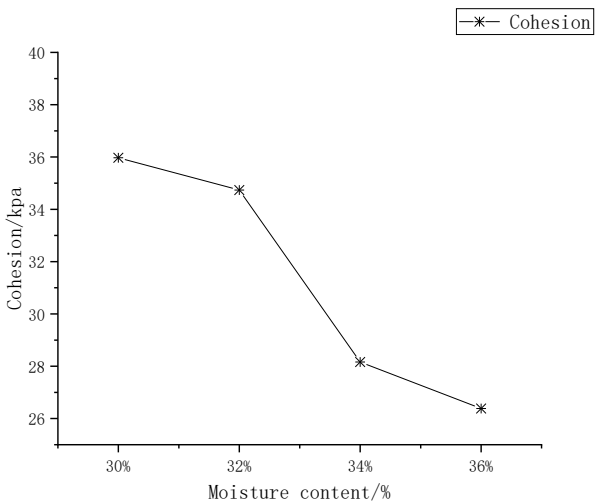

(a) Plain soil
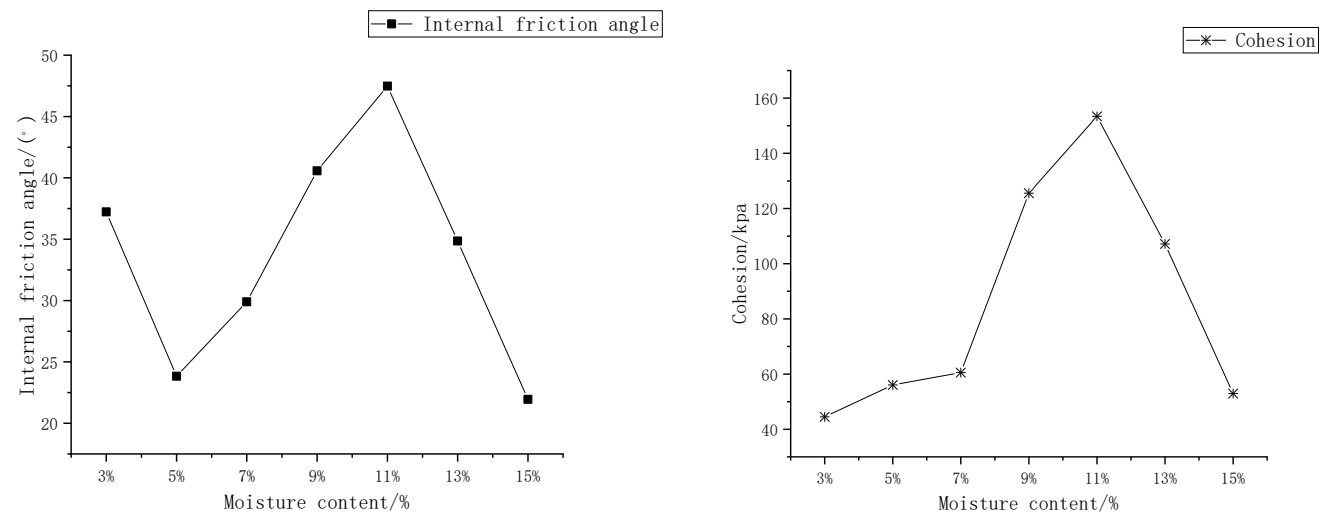

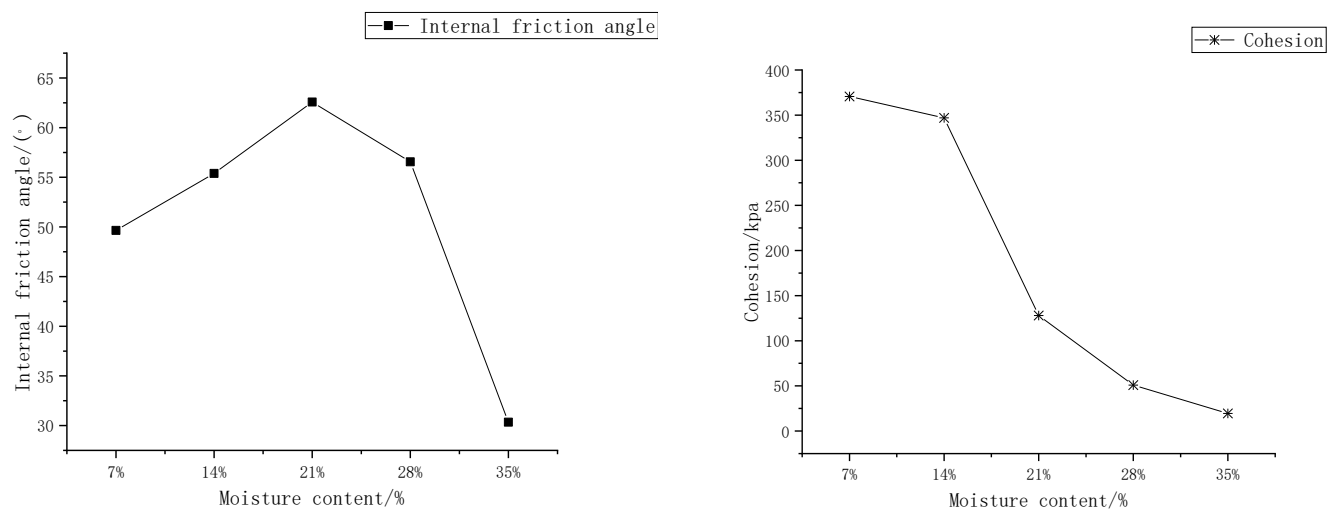

2

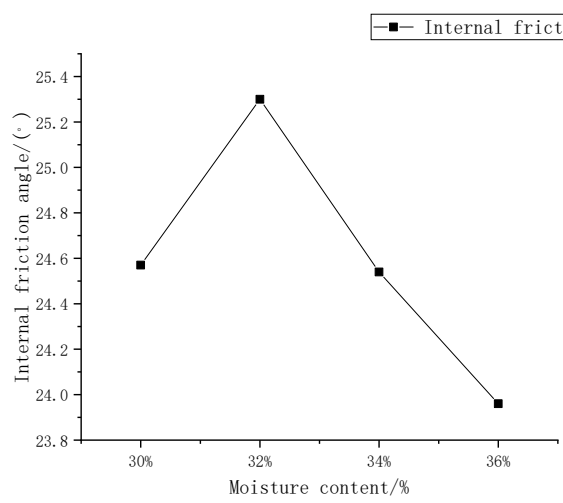

(c) Wood fibre composite soil

4

(d) Coarse sand composite soil

Note: The mixing amount of glutinous rice glue, wood fibre, and coarse sand are respectively $1.5 \%, 5 \%$, and $5 \%$ as examples.

Fig. 2 Changes of internal friction angle and cohesion of single composite soil under different water content conditions

\section{Shear strength analysis of single composite soil with different contents}

Figure 3 shows that under the vertical pressure range of 100-400 kPa, the shear strengths of composite soils with different contents, such as glutinous rice glue, wood fibre, and coarse sand, are greater than that of plain soil. With increasing glue content, the shear strength and internal friction angle of the glutinous rice glue composite soil first increase and then decrease. When the glue content is $1.5 \%$, the two values are the largest. Among them, the cohesive force shows a continuous increasing trend. However, the rate of increase in the high-content stage (1.5 2.5\%) is slower than that in the low-content stage $(0.5 \sim 1.5 \%)$ because the admixture of glue into the soil can promote the agglomeration of soil particles through the coagulation of the glue and improve the cohesion and internal friction angle. However, when the amount of glue is too high, the proportion of soft glue will increase to form a glue network, which separates and wraps the soil particles, reduces the contact area between the soil particles, and makes the soil form a "soft plastic" shape. Therefore, the shear strength is reduced. With increasing fibre content, the shear strength, internal friction angle and cohesive force of wood fibre composite soil show a 
continuous upward trend. When the fibre content is $5 \%$, the three values are relatively large, and

2 the maximum value is not reached. As the sand content increases, the shear strength and internal

3

4 friction angle of the coarse sand composite soil gradually increase, thereby reaching a maximum value at a content of $15 \%$ and then beginning to show a downward trend. When the sand content ranges from $5 \%$ to $15 \%$, coarse sand can contact the soil particles, and the internal friction angle will increase; when the sand content exceeds $15 \%$, since the particle size of the coarse sand itself is much larger than that of the soil particles, the mass and volume of the coarse sand in the composite soil increase, and the sand particles will interact with each other. It is difficult for the particles to come into close contact with each other; therefore, a certain void structure is formed, the internal friction angle begins to decrease, and the cohesive force is negatively related to the sand content. The greater the sand content is, the lower the cohesive force.

Table 3 Changes in shear strength of single composite soil under different content conditions

(kpa)

\begin{tabular}{cccccc}
\hline \multirow{2}{*}{ category } & & \multicolumn{4}{c}{ Vertical pressure /kpa } \\
& Content $/ \%$ & $100 \mathrm{kpa}$ & $200 \mathrm{kpa}$ & $300 \mathrm{kpa}$ & $400 \mathrm{kpa}$ \\
\hline Plain soil & -- & 75.98 & 117.22 & 158.46 & 199.71 \\
& $0.5 \%$ & 103.24 & 137.55 & 183.19 & 206.29 \\
Glutinous rice glue & $1.5 \%$ & 268.8 & 362.34 & 480.07 & 593.11 \\
composite soil & $2.5 \%$ & 199.95 & 233.53 & 235.51 & 271.98 \\
& $1 \%$ & 122.45 & 150.66 & 178.86 & 207.06 \\
Wood fibre & $2.5 \%$ & 292.78 & 381.46 & 470.15 & 558.83 \\
composite soil & $5 \%$ & 372.87 & 549.89 & 587.93 & 601.71 \\
& $5 \%$ & 71.96 & 119.23 & 166.50 & 213.77 \\
Coarse sand & $10 \%$ & 73.40 & 126.37 & 179.34 & 232.31 \\
composite soil & $15 \%$ & 74.59 & 130.84 & 187.10 & 243.35 \\
& $20 \%$ & 69.69 & 124.84 & 180.00 & 235.16 \\
\hline
\end{tabular}

Note: The moisture content of plain soil is $32 \%$; the moisture content of glutinous rice glue, wood fibre, and coarse sand are $11 \%, 14 \%$, and $32 \%$ respectively.
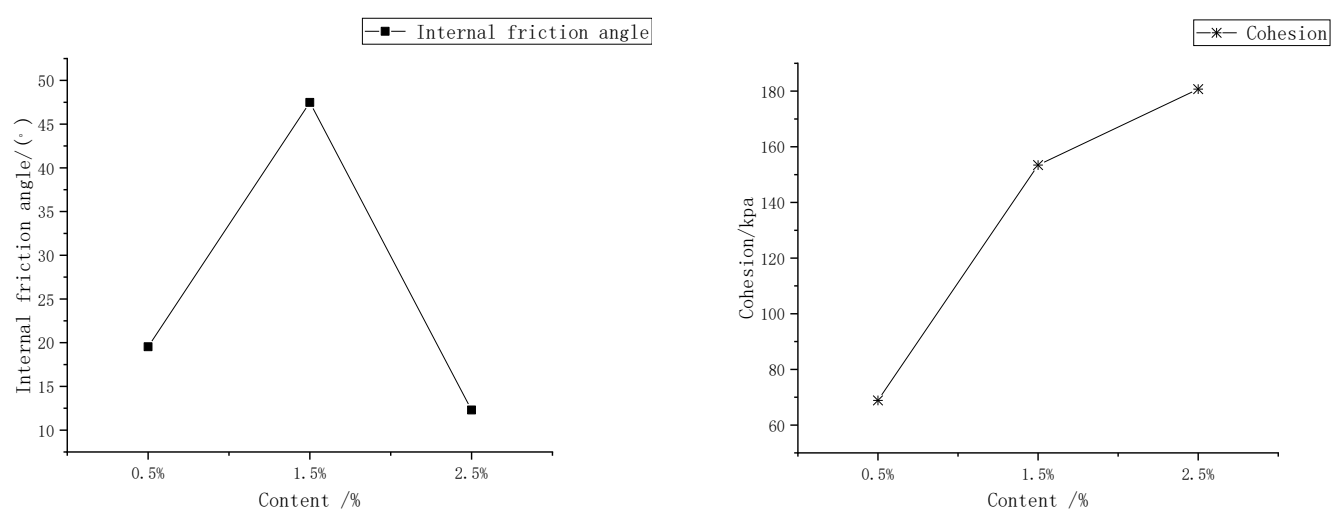

a. Glutinous rice glue composite soil 

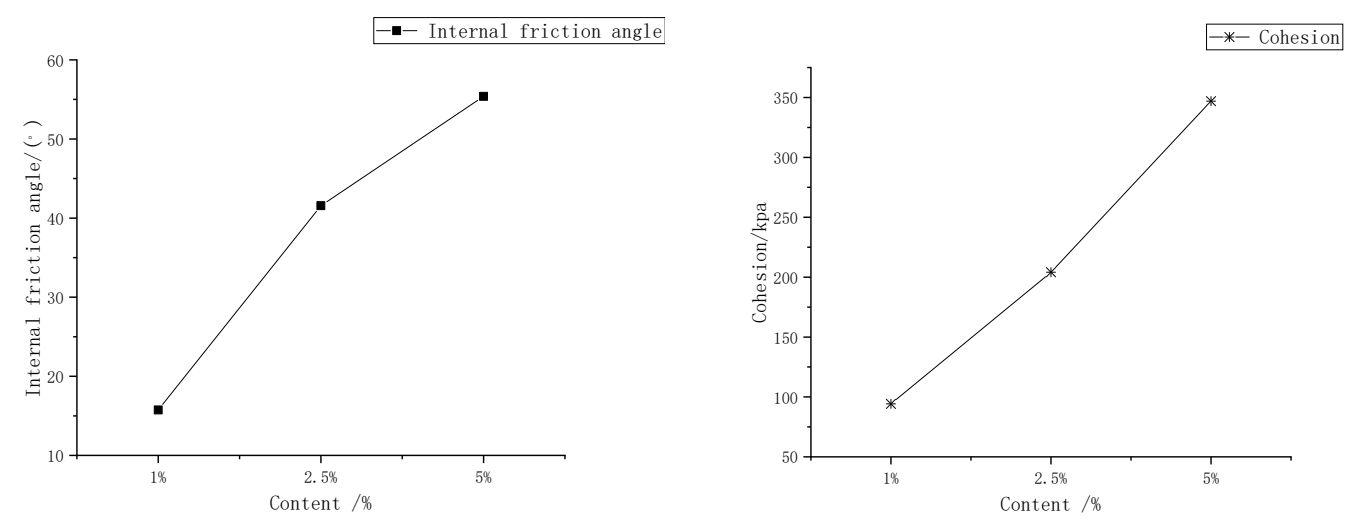

1

b. Wood fibre composite soil
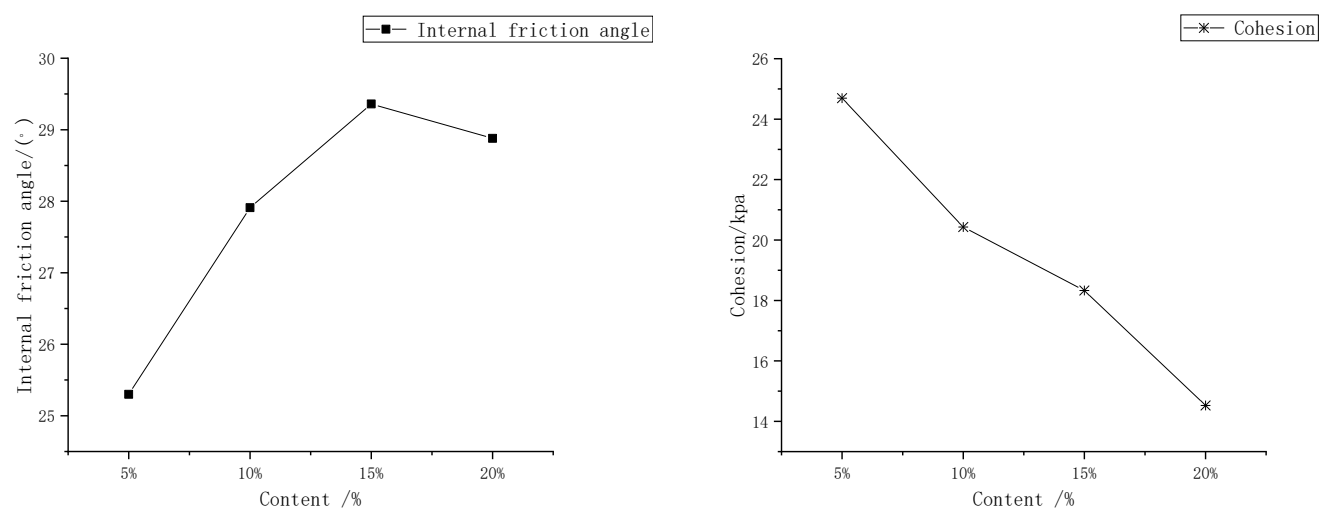

\begin{abstract}
c. Coarse sand composite soil
Note: The moisture content of plain soil is $32 \%$; the moisture content of glutinous rice glue, wood fibre, and coarse sand are $11 \%, 14 \%$, and $32 \%$ respectively.
\end{abstract}

Fig. 3 Shear strength changes of composite soil with different contents

\title{
Determination of the optimal ratio parameters of the mixed material composite soil
}

According to section 2.2, when the shear strength of the three glutinous rice glue, wood fibre, and coarse sand materials is the highest, the corresponding optimal contents are $1.5 \%, 52.5 \%$, and $15 \%$, respectively. The optimal content of the three materials is mixed with red soil to form a new mixed composite soil, and the shear strength of these mixtures is compared with the shear strength of a single composite soil(Fig.4). Under different water contents, the shear strength of mixed composite soil is greater than the shear strength of single composite soil with the optimal water content and optimal content of soil, and the shear strength decreases slowly with increasing water content. The internal friction angle of the mixed composite soil first increases and then decreases. This is mainly due to the effect of water on glutinous rice glue. In the water content range of $11-14 \%$, the glutinous rice glue is gradually diluted and transforms between the colloidal state and the fluid state, which is caused by the change in the soil structure. The cohesive force of the mixed composite soil shows a continuous decreasing trend. When the moisture content is $11 \%$, the cementation effect of the glutinous rice glue is fully exerted, and the cohesive force is the largest; when the moisture content is $14 \%$, the cohesive force of the mixed composite soil is lower than 
that of the wood fibre composite soil. This may be because the glutinous rice glue in the soil occupies a certain proportion, it is diluted by water, and the binding effect of the wood fibres is affected. Overall, the internal friction angle and cohesion of mixed composite soil are better than those of single composite soil.

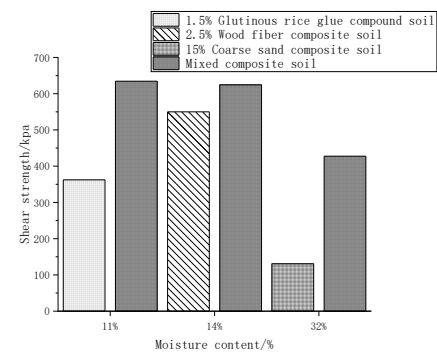

(a)Shear strength

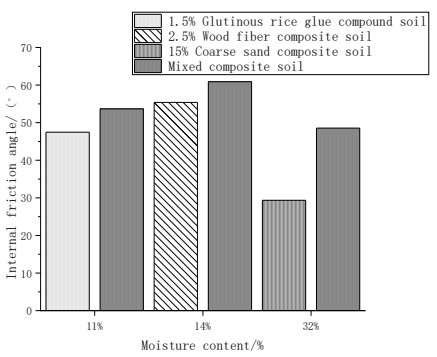

(b)Internal friction angle

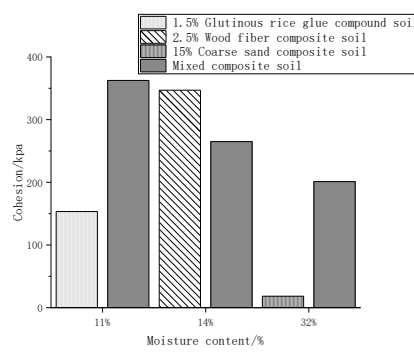

(c)Cohesion

Note: The vertical pressure corresponding to the shear strength in a picture is $200 \mathrm{kpa}$.

Fig. 4 Change of shear strength of mixed material composite soil

In the improvement of sloping farmland, in addition to considering the shear strength of the slope, the suitability of plant growth should be considered. During the experiment (Figure 3-b), it was found that the content of wood fibre increased, and the shear strength and cohesive force continued to increase. The contribution rate to the soil consolidation ability was greater than that of glutinous rice glue and coarse sand, but too high of a wood fibre content would cause soil compaction, which is not conducive to plant growth. Therefore, the wood fibre content for the optimal ratio parameters of the shear strength of the abovementioned mixed composite soil was designed to be $1.5 \%, 2.5 \%, 4 \%$ and $5 \%$ for pot experiments to test the growth suitability of plants, as shown in Fig.5 (an image was taken when the plant was planted for approximately 3 months, and the planted herb was Cynodon dactylon). According to the test results, the total biomasses of $\mathrm{A}: \mathrm{B}_{1}: \mathrm{C}, \mathrm{A}: \mathrm{B}_{2}: \mathrm{C}, \mathrm{A}: \mathrm{B}_{3}: \mathrm{C}$, and $\mathrm{A}: \mathrm{B}_{4}: \mathrm{C}$ were $153.06 \mathrm{~g} / \mathrm{m}^{2}, 158.22 \mathrm{~g} / \mathrm{m}^{2}, 37.65 \mathrm{~g} / \mathrm{m}^{2}$ and $11.42 \mathrm{~g} / \mathrm{m}^{2}$, respectively. $A: B_{1}: C$ and $A: B_{2}: C$ significantly increased the total biomass, the value of $A: B_{2}: C$ was slightly higher than that of $A: B_{1}: C$, and the plants grew well (Table 4).

Table 4 content ratio of each improved material and herbaceous biomass of mixed improved composite soil used for grass planting

\begin{tabular}{ccccc}
\hline \multirow{2}{*}{$\begin{array}{c}\text { Different mixtures of improved soil } \\
\text { used for growing grass }\end{array}$} & $\begin{array}{c}\text { Add the content/\% } \\
\text { glue }\end{array}$ & B:Wood fibre & C:Coarse sand & Biomass(g) \\
\hline 1 & 1.5 & 1.5 & 15 & 153.06 \\
2 & 1.5 & 2.5 & 15 & 158.22 \\
3 & 1.5 & 4 & 15 & 37.65 \\
4 & 1.5 & 5 & 15 & 11.42 \\
\hline
\end{tabular}




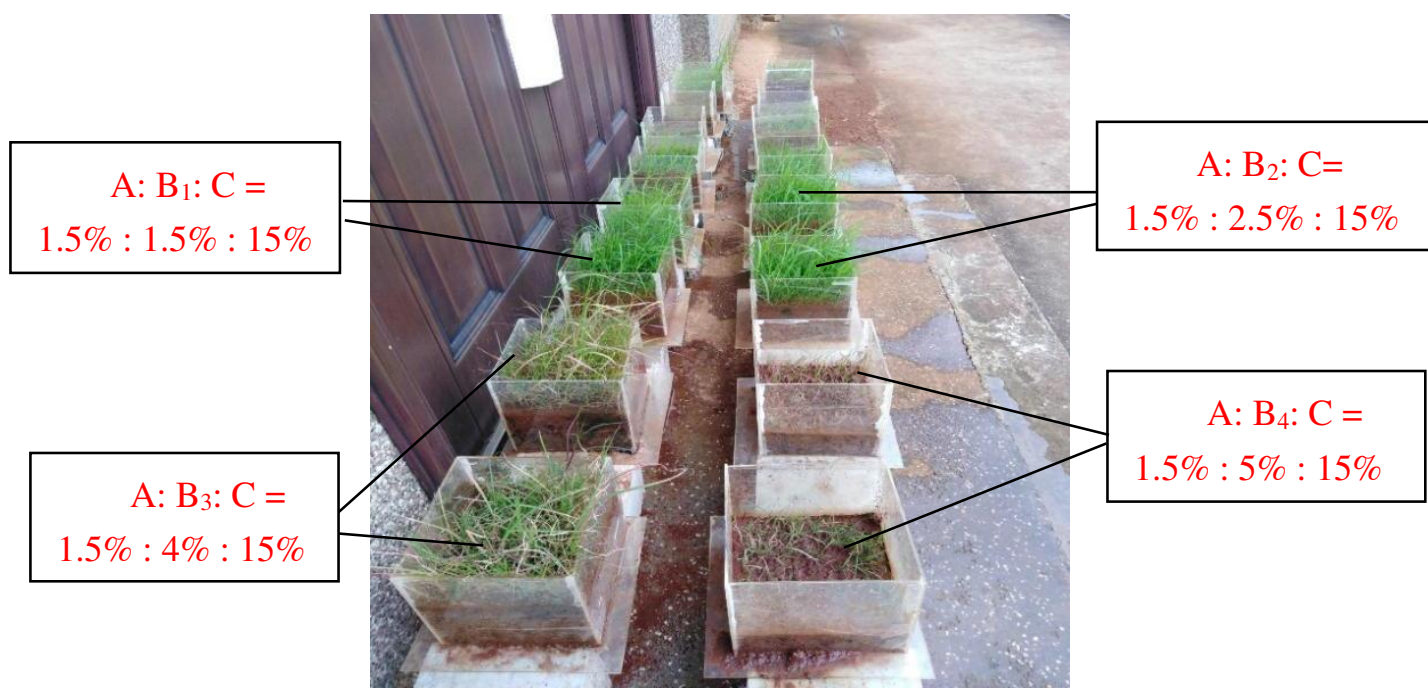

Note: $\mathrm{A}$ is glutinous rice glue; $\mathrm{B}$ is wood fibre; $\mathrm{C}$ is coarse sand.

Fig. 5 Planting conditions of mixed composite soil with different ratios

\section{Case analysis}

\section{Project area overview}

The project area is located in Binchuan County, which belongs to the dry-hot valley of the Jinsha River of China (Fig. 6). It is located between $100^{\circ} 16^{\prime} \sim 100^{\circ} 59^{\prime}$ east longitude and $25^{\circ} 32^{\prime} \sim 26^{\circ} 12^{\prime}$ north latitude. The altitude is 1410 metres to 1558 metres, and the landform is a red soil hilly area. It has a semiarid monsoon climate in the southern subtropical zone. The average rainfall is $560.9 \mathrm{~mm}$, the annual average temperature is $17.9^{\circ} \mathrm{C}$, and the frost-free period is 294 days. This project is a land consolidation demonstration project. The total land area is 426.85 hectares, of which 393.74 hectares are wasteland, 10.61 hectares are erosion bare land, and 22.50 hectares are dry land. After the implementation of the land improvement project, an area of 406.84 hectares of slope-to-terraced conversion was realized, with a slope of $10-20^{\circ}$ and a total slope area of 115.27 hectares.

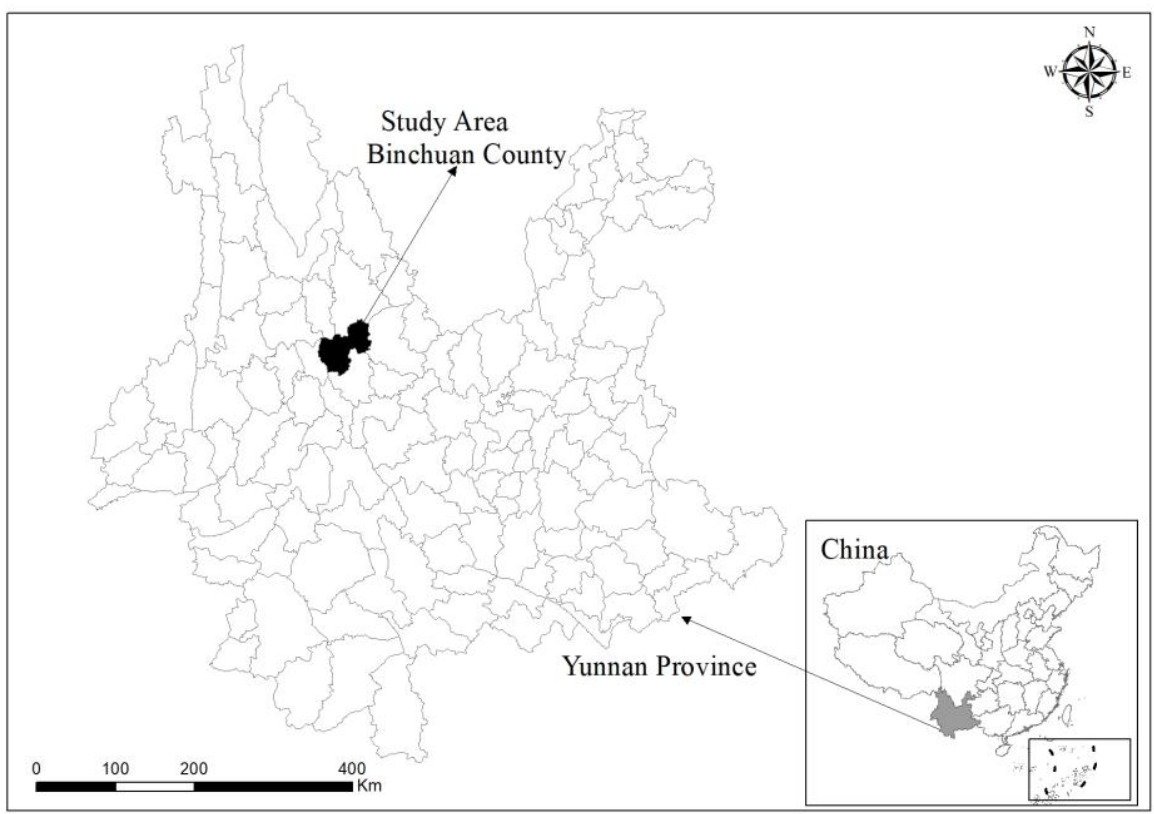


2

\section{Analysis of the application results}

According to the actual situation of the project area and the optimal content ratio parameter of 1.5\%:2.5\%:15\% determined by the three composite materials of glutinous rice glue, wood fibre and coarse sand, the application of terrace embankment slope treatment was performed. Three slopes of $10^{\circ}, 15^{\circ}$, and $20^{\circ}$ were set, and the SIOPE/W slope analysis module in Geostudio software was used to analyse and process the slope safety factors of single composite soil and mixed composite soil(Table 5).

Under different slopes, the minimum safety factor of the slope for the three single composite soils showed an upward trend before reaching the optimal water content and showed a downward trend after the optimal water content was achieved. At the optimal moisture content, the minimum safety factor of the slope was ranked in the following order: wood fibre composite soil> glutinous rice glue composite soil> coarse sand composite soil. The minimum safety factor of the slope of the mixed composite soil for the three improved materials increased with the increase in water content, it was the largest when the water content was $11 \%$, and then it gradually decreased. When the water content was $14 \%$, the minimum slope of the mixed composite soil was achieved, the safety factor was slightly lower than that of wood fibre composite soil, and it was higher than that of single composite soil under other moisture content conditions. However, when the moisture content increased to $28 \%$, the minimum safety factor of the slope of composite soil was less than that of wood fibre, and the overall stability was better. The composite soil of mixed materials (1.5\% glutinous rice glue, $2.5 \%$ wood fibre, $15 \%$ coarse sand) was applied to the slope surface of the slope of the farmland, which can effectively enhance the stability of the sloping farmland slope (Fig.7).

Table 5 Minimum slope safety factors of composite soil with different content

\begin{tabular}{|c|c|c|c|c|c|}
\hline $\begin{array}{c}\text { Slope } \\
1^{\circ}\end{array}$ & $\begin{array}{c}\text { Moisture } \\
\text { content / \% }\end{array}$ & $\begin{array}{l}\text { 1.5\%A:2.5\%B:15\%C } \\
\text { mixed composite soil }\end{array}$ & $\begin{array}{c}1.5 \% \mathrm{~A} \\
\text { composite soil }\end{array}$ & $\begin{array}{l}2.5 \% \text { B Composite } \\
\text { soil }\end{array}$ & $\begin{array}{c}15 \% \mathrm{C} \\
\text { composite soil }\end{array}$ \\
\hline \multirow{6}{*}{$10^{\circ}$} & $5 \%$ & 20.550 & 5.671 & & \\
\hline & $11 \%$ & 22.749 & 14.301 & & \\
\hline & $14 \%$ & 22.092 & & 23.512 & \\
\hline & $28 \%$ & 16.585 & & 11.652 & \\
\hline & $32 \%$ & 14.160 & & & 3.095 \\
\hline & $36 \%$ & 12.224 & & & 2.433 \\
\hline \multirow{6}{*}{$15^{\circ}$} & $5 \%$ & 13.649 & 3.717 & & \\
\hline & $11 \%$ & 14.829 & 9.369 & & \\
\hline & $14 \%$ & 14.496 & & 15.335 & \\
\hline & $28 \%$ & 10.874 & & 7.791 & \\
\hline & $32 \%$ & 9.288 & & & 2.069 \\
\hline & $36 \%$ & 8.031 & & & 1.607 \\
\hline \multirow{6}{*}{$20^{\circ}$} & $5 \%$ & 10.159 & 2.799 & & \\
\hline & $11 \%$ & 11.263 & 7.060 & & \\
\hline & $14 \%$ & 10.899 & & 11.637 & \\
\hline & $28 \%$ & 8.184 & & 5.872 & \\
\hline & $32 \%$ & 6.987 & & & 1.539 \\
\hline & $36 \%$ & 6.026 & & & 1.197 \\
\hline
\end{tabular}




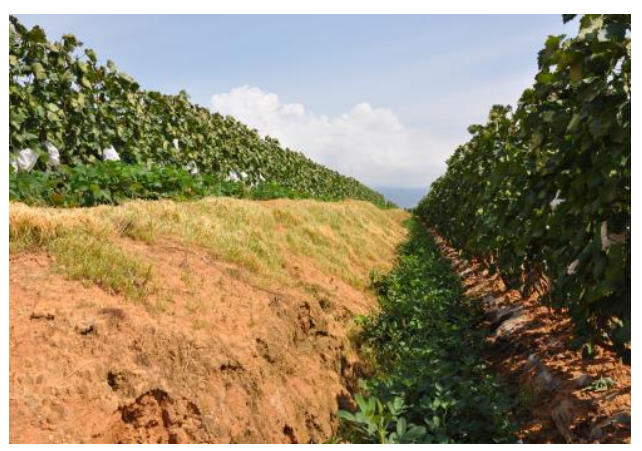

(a1) Before slope improvement

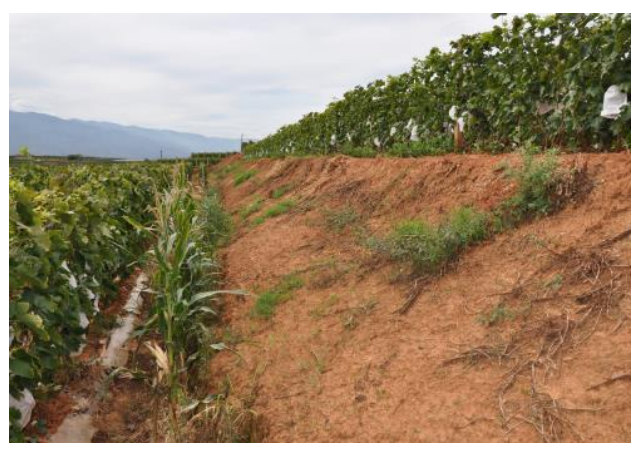

(b1)Before slope improvement

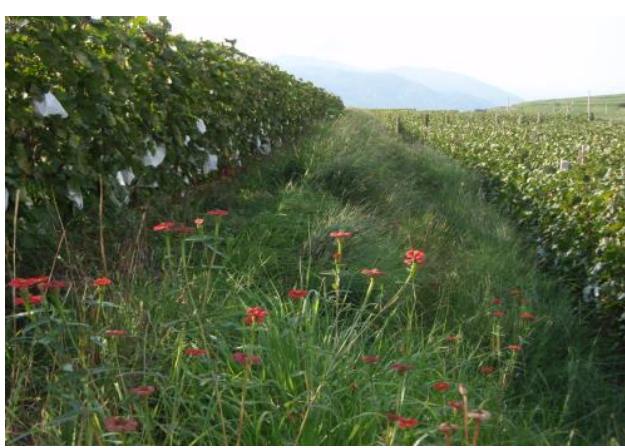

(a2) After slope improvement

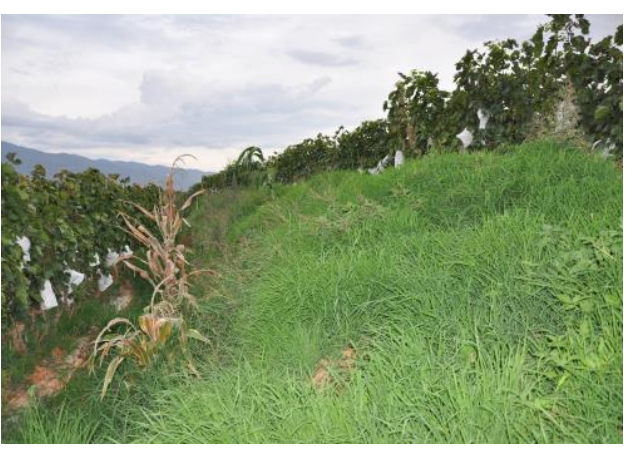

(b2) After slope improvement

Fig. 7 Comparison of planting grass before and after application of mixed improved materials

\section{Conclusion}

(1) Different moisture contents have different effects on the three soil improvement materials. When stabilizing the soil, to facilitate the full combination of the amendment and the soil particles, the optimal moisture contents of glutinous rice glue composite soil, wood fibre composite soil, and coarse sand composite soil are $11 \%, 14 \%$ and $32 \%$, respectively. After stabilizing the soil, the modifier and soil particles combine to form a certain strength, and the effect of the changes in water content on the soil is also reduced. Among them, the shear strength of plain soil is relatively stable when the water content is in the range of $30-32 \%$ and then slowly decreases, the internal friction angle does not change significantly, and the cohesive force continues to decrease. The internal friction angle does not change significantly, and the cohesive force continues to decrease. The shear strength and internal friction angle of the glutinous rice glue composite soil showed a trend of first decreasing, then increasing and then decreasing. The cohesive force increased slowly at a water content of 3\% 7\%, increased rapidly at the 7\% 15\% stage and then decreased rapidly. When the moisture content was $11 \%$, the shear strength, internal friction angle, and cohesive force all reach maximum values; the shear strength and cohesive force of wood fibre composite soil showed a significant decline after the moisture content increased to $14 \%$. When the water content increased to $28 \%$, the internal friction angle showed a rapid decreasing trend; the shear strength, internal friction angle and cohesive force of the coarse sand composite soil first increased and then decreased. When the water content was $32 \%$, the three maximum values were reached.

(2) The difference in the content of soil improvement materials will affect the soil structure. Compared with plain soil, adding different improvement materials can increase the shear strength 
of the soil. As the glue content increases, the shear strength and internal friction angle of glutinous rice glue first increase and then decrease. When the glue content is $1.5 \%$, the two values are the largest. When the glue content is too high, the soil particles will be separated and wrapped, thereby reducing the contact area between the soil particles and making the soil form a "soft plastic" shape; with the increase in fibre content, the shear strength and internal friction angle and cohesive force both show a continuous upward trend. When the fibre content is $5 \%$, the three values are larger; as the sand content increases, the shear strength and internal friction angle of the coarse sand composite soil gradually increase. At $15 \%$, the content reaches a maximum value and then begins to show a downward trend. The cohesion and sand content are negatively correlated, and the higher the sand content is, the lower the cohesion.

(3) The shear strength of mixed (1.5\% glutinous rice glue, $5 \%$ wood fibre, and $15 \%$ coarse sand) composite soil is greater than the shear strength of the optimal moisture content and optimal content of a single composite soil; combined with plant growth suitability, when the mixing ratio parameters are adjusted, the total biomass of the composite soil with mixed materials $(1.5 \%$ glutinous rice glue, $2.5 \%$ wood fibre, and $15 \%$ coarse sand) is the highest, which is suitable for plant growth.

(4) Combined with the actual case of slope farmland consolidation, the minimum safety factor of the slope of the mixed (1.5\% glutinous rice glue, 2.5\% wood fibre, and 15\% coarse sand) composite soil is better than the three slopes of $10^{\circ}, 15^{\circ}$ and $20^{\circ}$ The slope of single composite soil has better overall stability than that of composite soil under different water contents.

\section{Declarations}

The authors declare that they have no known competing financial interests or personal relationships that could have appeared to influence the work reported in this paper.

\section{Acknowledgements}

This research is jointly supported by the Natural Science Foundation of China (grant numbers 41867038 and 41662021), and open fund by "Technical Innovation Team for land allocation and ecological consolidation in Southwest diversified regions" of ministry of natural resources of China(grant number YNTD2018KF05). For help with the collection data and revise this article, we would like to thanks Professor Jianxin Yu of Yunnan Agricultural University.

\section{Reference}

Xiao H, Huang J, Ma Q, Wan J, Li L, Peng Q, Rezaeimalek S(2017) Experimental study on the soil mixture to promote vegetation for slope protection and landslide prevention. Landslides 14 (1):287-297. https://doi.org/10.1007/s10346-015-0634-х

Le ZZ, Qu ZZ, Wang LP, Gao XY, He Q(2020) Effect of flocculating Yellow river sediment with biochar on water-salt transport and hydraulic characteristic parameters of saline soil. Journal of Soil and Water Conservation 34 (03):326-331. https://doi.org/10.13870/j.cnki.stbcxb.2020.03.047

Liu HJ, Liu JH, Xu ST, Guo M(2012)Effects of soil amendments on soil moisture and oat yield. Journal of Irrigation and Drainage 31(03):125-128. https://doi.org/ 10.13870/j.cnki.stbcxb.2012.05.034

Pan YH, Lei YW, Zhang QW, Liu JG, Xia WS(2003)Effects of soil structure modifiers on soil hydrodynamic 
parameters. Transactions of the Chinese Society of Agricultural Engineering (04):37-39. https://doi.org/ 10.3321/j.issn:1002-6819.2003.04.008

Sun YQ, Wang MY, Zhang L, Chen X, Zhang ZQ, Shi XZ, Xu SX, Sun WX, Ban GJ, Xia ZW(2020)Particle size effect of foamy sand on improving pore structure of clayey yellow soil. Soil 52(3):597-602. https://doi.org/10.13758/j.cnki.tr.2020.03.025

Xi YQ, Zhao Y, Li SY(2018)Effect of three soil amendments on shear strength of aeolian sand soil. Chinese Journal of Soil Science 55(06):1401-1410. https://doi.org/10.11766/trxb201802030436

Peng X, Tong X, Hao L, Wu F(2019)Applicability of biochar for limiting interrill erosion and organic carbon export of sloping cropland in a semi-arid area of China. Agriculture, Ecosystems and Environment. https://doi.org/280:68-7610.1016/j.agee.2019.04.021

Chai GQ, Zhao YN, Huang XC, Zhang YQ, Shi XJ(2017)Different carbon-based improver improve the water storage and moisture conservation ability of purple soil. Journal of Soil and Water Conservation 31(001):296-302. https://doi.org/10.13870/j.cnki.stbcxb.2017.01.049

Ji HL, Yan R, Li YD, Fang YM, Yang LZ, Wu YH(2011)Study on the effect of soil amendments on phosphorus loss. Soil 43(02):203-209. https://doi.org/10.13758/j.cnki.tr.2011.02.004

Pan YH, Lei YW, Gu XY,(2008)Study on practicability of interval mulching combined with soil conditioner on sloping land. Journal of Soil and Water Conservation (03):187-191. https://doi.org/10.3321/j.issn:1009-2242.2008.03.038

Shao FF, Wu JH(2020)Effects of vermicompost on the characteristics of runoff sediment yield and nitrate nitrogen loss in sloping farmland in loess region. Journal of Soil and Water Conservation 34(01):71-77. https://doi.org/10.13870/j.cnki.stbcxb.2020.01.011

Zhang BX, He FH, Zhu QH, Peng XH(2017)Effect of organic fertilizer on sediment yield in red soil slope. Soil 49(06):1237-1242. https://doi.org/10.13758/j.cnki.tr.2017.06.025

Li X(2017)Analysis of relationship between soil shear strength and influencing factors of different land use types. Master, Shenyang Agricultural University.

Du MC, Li JT, Li SL, Li JQ(2018)Effects of different tillage methods on soil pore structure and penetration strength of cultivated land in South China Slope. Journal of Guangzhou University (Natural Science) 17(06):74-80. https://doi.org/10.3969/j.issn.1671-4229.2018.06.014

Yuan ST, Liu XY, Wen CJ, Pan MC(2015)Effects of rainfall and slope on soil erosion intensity of cultivated land on the eastern slope of Yunnan. Journal of Anhui Agricultural Sciences 43(09):234-237. https://doi.org/10.3969/j.issn.0517-6611.2015.09.083

Fan XJ(2019)Simulation of soil phosphorus loss on weathered granite slope with different erosion intensity. Master, Zhejiang University.

Zhang JL, Shi DM, Liu Y, Ren YH, Pu CJ(2020)Effect of soil bulk density and water content on shear strength of cultivated layer on purple soil slope. Journal of Soil and Water Conservation 34(03):162-167,174. https://doi.org/10.13870/j.cnki.stbcxb.2020.03.025

Ding WB, He WJ, Shi DM, Jiang GY, Jiang P, Chang SG(2017)Effect of wetting and drying on soil shear strength of biological ridge on purple soil slope. Acta Prataculturae Sinica 26(06):56-67. https://doi.org/10.11686/cyxb2016298

Pu YL, Xie DT, Ni JP, Wei CF, Lin CW(2014)Effect of hedgerow pattern on soil shear strength and scouring resistance of sloping farmland in purple soil area. Scientia Agricultura Sinica 47(05):934-945. https://doi.org/10.3864/j.issn.0578-1752.2014.05.010

Shi DM, Jiang P, He WJ, Ding WB, Wang SS, Peng XD(2016)Response of soil shear strength to wetting and drying on biological ridge of purple soil slope. Transactions of the Chinese Society of Agricultural Engineering 
32(24):139-146. https://doi.org/10.11975/j.issn.1002-6819.2016.24.018

Jin L, Zeng Y, Xia L, Ye Y(2017)Experimental and numerical investigation of mechanical behaviors of cemented soil-rock mixture. Geotechnical and Geological Engineering 35(1):337-354. https://doi.org/ 10.1007/s10706-016-0109-4

Tang JY, Xu DS, Liu HB(2018)Influence of gravel content on shear behavior of soil-rock mixture. Rock and Soil Mechanics 39(01):93-102. https://doi.org/10.16285/j.rsm.2017.1527

Xu WJ, Xu Q, Hu RL(2011)Study on the shear strength of soil-rock mixture by large scale direct shear test. International Journal of Rock Mechanics and Mining Sciences 48(8):1235-1247. https://doi.org/10.1016/j.ijrmms.2011.09.018

Xu WJ, Zhang HY(2013)Research status and development trend of soil-rock mixture. Advances in Science and Technology of Water Resources 33(1):80-88. https://doi.org/10.3880/j.issn.1006-7647.2013.01.019

Yang JH, Dong JY, Huang ZQ, Zheng ZG, Qi D(2016)Experimental study on shear strength characteristics of compoundments under different gravel content. Chinese Journal of Geotechnical Engineering 38(S2):161-166. https://doi.org/10.11779/CJGE2016S2026

Liu JF, Su YH(2017)Analyses of the Strength Characteristics of Solidified Desert Aeolian Sandy Soil. Journal of Highway and Transportation Research and Development (English Edition) 11(2):32-36. https://doi.org/10.1061/JHTRCQ.0000564

Guo GS, Zhang Y, Du S(2017)Grassroots-level shear strength experimental study of aeolian sand with cement. Science Technology \& Engineering (15):322-326. https://doi.org/10.3969/j.issn.1671-1815.2017.15.053

Cheng JM(2014)Experimental study on new hardener technology for strengthening loess slope. Taiyuan University of Technology. (In Chinese)

Maliakal T, Thiyyakkandi S(2013)Influence of Randomly Distributed Coir Fibres on Shear Strength of Clay. Geotechnical and Geological Engineering 31(2):425-433. https://doi.org/10.1007/s10706-012-9595-1

Estabragh A R, Bordbar A T, Javadi A A. A Study on the Mechanical Behavior of a Fibre-Clay Composite with Natural Fibre[J]. Geotechnical and Geological Engineering, 2013, 31(2):501-510.

He YL(2018)Research on shear strength of fibre reinforced soil and stability of embankment slope. Jilin University. https://doi.org/CNKI:CDMD:2.1018.214863

Nanjing Hydraulic Research Institute(1999)Industry standard of the People's Republic of China: Standard of geotechnical test method GB/T50123-1999. Beijing: China Planning Publishing House. (In Chinese)

He B, Song S(2019)Analysis of Slope Stability and Selection of Support Scheme Based on Geostudio Theory. Geology and Exploration 55(05):1329-1335. https://doi.org/10.12134/j.dzykt.2019.05.021 